\title{
Nuevos crucificados relacionados con Pablo de Rojas y su círculo en el entorno granadino
}

José Antonio Peinado Guzmán

Universidad de Granada

\section{RESUMEN}

Con el escultor Pablo de Rojas da comienzo en Granada la escuela granadina de escultura. En torno a su figura fueron formándose una serie de artistas que bebieron del clasicismo de sus formas y pusieron los puntales del posterior Barroco. Uno de los modelos iconográficos más exitosos de aquel núcleo fue, sin duda, el de Cristo Crucificado. Este trabajo pretende sacar a la luz nuevas piezas desconocidas de este prototipo, diseminadas por la geografía granadina, y que pueden ser relacionadas con el genial maestro Rojas o con algunos de sus discipulos durante.

\section{PALABRAS CLAVE:}

Pablo de Rojas, Granada, Siglos XVI-XVII, Diego de Vega, Escultura.

\section{ABSTRACT}

With the sculptor Pablo de Rojas the Granada School of sculpture starts in Granada. Lathe in his figure were forming a series of artists who drank from the classicism of its forms and put the later Baroque Struts. One of the most successful iconographic models of that core was, without a doubt, the crucified Christ. This paper attempts to bring to light new unknown parts of this prototype, disseminated by the Granada geography, and that they may be related with the great master Rojas or some of his disciples during.

\section{KEY WORDS:}

Pablo de Rojas, Granada, 16th-17th centuries, Diego de Vega, Sculpture. 


\section{Introducción}

La escuela granadina de escultura, tradicionalmente, ha situado como punto de arranque de la misma la figura de Pablo de Rojas (1549$1611)^{1}$. El que fuera maestro del genial Juan Martínez Montañés (1568-1649), se erigirá como el gran imaginero de los albores artísticos granadinos, creando una ingente variedad de prototipos iconográficos, así como un legado de escultores en forma de escuela. Seguidores del mismo serán otros grandes de las gubias como Bernabé de Gaviria o Alonso de Mena, y también artistas menos conocidos como Martín de Aranda, Diego de Vega o los hermanos Juan y Antonio Gómez.

Dentro de la diversidad de imágenes que realiza, tienen especial mención las tallas de corte pasionario: Crucificados, Nazarenos, Yacentes o simulacros de Cristo atado a la columna, componen un repertorio de esculturas que sirvieron a la perfección para su misión evangelizadora, siguiendo los dictámenes del Concilio de Trento.

Asimismo, diferentes factores influyen en la importancia que llegó a alcanzar este artista nacido en Alcalá La Real (Jaén). Por un lado, la muerte de Diego de Siloe en 1563 dejó a Granada huérfana de un referente artístico de peso. Bartolomé Ordóñez, Felipe Bigarny o Jacopo Florentino, años atrás, habían trabajado de forma muy puntual en

1 Como bibliografía básica sobre Pablo de Rojas: GILA MEDINA, Lázaro, "Los Raxis: importante familia de artistas del Renacimiento Andaluz. A ella perteneció el gran escultor Pablo de Rojas", en Archivo Español de Arte, 238 Madrid, 1987, pp. 167-178; JUAN LOVERA, Carmen, "Pablo de Rojas: primer maestro y paisano de Juan Martínez Montañés", en Boletín de Bellas Artes, XVII, Sevilla, 1989, pp. 109-116; GILA MEDINA, Lázaro, "En torno a los Raxis Sardo: Pedro de Raxis y Pablo de Rojas en la segunda mitad del siglo XVI", en Atrio: Revista de Historia del Arte, 4, Sevilla, 1992, pp. 35-48; MARTÍNEZ JUSTICIA, Ma José, “La adaptación al gusto de la época: un criterio siempre vigente: a propósito de un bello grupo escultórico del alcalaíno Pablo de Rojas", en X Congreso de Conservación y Restauración de Bienes Culturales: Cuenca 29, 30 de septiembre, 1, 2 de octubre de 1994, Ministerio de Cultura, Secretaría del Congreso de Conservación y Restauración de Bienes Culturales, Cuenca, 1994, pp. 137-147; SÁNCHEZ-MESA MARTÍN, Domingo, "La escultura en el retablo: sobre el romanismo de $\mathrm{Pa}$ blo de Rojas", en Archivo hispalense: Revista histórica, literaria y artística, tomo 82, 289, Sevilla, 1999, pp. 231250; MARTÍN ROSALES, Francisco y ROSALES FERNÁNDEZ, Francisco, Pablo de Rojas. Escultor de imaginería. Maestro de Juan Martínez Montañés, Gráficas La Paz, Alcalá La Real, 2000; LÓPEZ-GUADALUPE MUÑOZ, Juan Jesús, "Mística y naturalismo en la escultura andaluza del Quinientos: el Nazareno de Pablo de Rojas”, en Bo- la capital granadina. De igual modo, los discípulos del burgalés, Diego de Aranda, Baltasar de Arce o Diego de Pesquera, o bien su labor artística fue exigua, o pronto marcharon a otras ciudades como es el caso del último. En esta tesitura, pues, se entremezclaron la falta de escultores notables en la zona, el buen hacer de sus gubias, así como la necesidad del exorno de un sinfín de templos. No olvidemos que en numerosas localidades aún se estaba terminando el revestimiento de sus iglesias con retablos e imágenes tras la Reconquista, y que a esto hay que unir la recién concluida rebelión de Las Alpujarras, finalizada en 1571. Todas estas circunstancias terminaron por convertir a Pablo de Rojas en el referente escultórico de la Granada de finales del siglo XVI y principios del Seiscientos.

Así pues, y como se ha referido, dentro de los modelos escultóricos más señeros de su obra, hemos de mencionar su nutrido muestrario de Crucificados. En este sentido, Pablo de Rojas, a la hora de plasmar la iconografía de Cristo en la cruz, se inspira claramente en fuentes como el modelo romanista de Leoni para el retablo mayor de San Lorenzo de El Escorial, u otras de componente gráfico como las estampas de Calvarios de Johan Sadeler I, los tipos pintados por El Greco o incluso algún grabado de Hieronymus Wierix. Y no ha de olvidarse tampoco la enorme influencia de Miguel Ángel, a partir de los dibujos de crucificados para Vittoria Colon-

letín de Arte, 26-27, Málaga, 2005-2006, pp. 249-282; SÁNCHEZ LÓPEZ, Juan Antonio y GALISTEO MARTÍNEZ, José, "Orto y esplendor de Granada: los hermanos Juan y Antonio Gómez, escultores del círculo de Pablo de Rojas”, en Cuadernos de Arte de la Universidad de Granada, 38, Granada, 2007, pp. 81-98; CRUZ CABRERA, José Policarpo, "La escultura quinientista granadina: de sus albores a $\mathrm{Pa}$ blo de Rojas", en La escultura del primer naturalismo en Andalucia e Hispanoamérica (1580-1625), Editorial Arco/Libros, Granada, 2010, pp. 95-114; LÓPEZ-GUADALUPE MUÑOZ, Juan Jesús, "Pablo de Rojas, encrucijada de las escuelas andaluzas", en La escultura del primer naturalismo, op. cit., pp. 137-174; SÁNCHEZ LÓPEZ, Juan Antonio, "Pablo de Rojas y la escultura del siglo XVI en Málaga. La difusión de una maniera”, en La escultura del primer naturalismo, op. cit., pp. 411-454; PEINADO GUZMÁN, José Antonio, "Nuevos datos sobre la Inmaculada de la iglesia parroquial de San Ildefonso de Granada, una imagen de Pablo de Rojas", en Boletín de Arte, 32-33, Málaga, 20112012, pp. 667-673; CRUZ CABRERA, José Policarpo, "Fuentes visuales en la configuración de la escultura quinientista granadina", en Arte y cultura en la Granada renacentista y barroca: la construcción de una imagen clasicista, Universidad de Granada, Granada, 2014, pp. 185224; LÓPEZ-GUADALUPE MUÑOZ, Juan Jesús, “Ut Sculptura Pictura. La integración de las artes plásticas en el primer barroco granadino", en Arte y cultura en la Granada, op. cit., pp. 395-432. 
na, hacia 1540 y 1556, respectivamente, ambos en el British Museum ${ }^{2}$. Asimismo, tampoco se pueden dejar de lado las pinturas que Rojas pudo conocer de Juan Sánchez Cotán, de su primera estancia granadina (1604-1605), como por ejemplo el Crucificado que coronaba el retablo de la Sala Capitular de La Cartuja granadina ${ }^{3}$. Y si apuramos más, pudo también tener conocimiento de la obras relacionadas con Pedro Machuca. Ejemplo de ello podría ser el Calvario del retablo de San Francisco que se halla en la parroquial de la granadina localidad de Padul, una tabla atribuida a un discípulo de aquél, Juan de Palenque, de mediados del siglo $\mathrm{XVI}^{4}$. Por tanto, el influjo italiano es evidente en su obra (no olvidemos que su ascendencia italiana, concretamente de Cerdeña, le permitió conocer de primera mano el universo renacentista de los grandes artistas de la época). De igual modo, como sostenemos, los referentes pictóricos y los grabados de aquel período también supusieron una fuente de inspiración interesante en su escultura. Incluso, incidiendo en este aspecto, podría ser probable que conociese, puesto que se educó en pleno apogeo del Humanismo, alguna obra de carácter médico como las que escribiera en la segunda mitad del siglo XVI Juan Valverde de Amusco, y cuyas ilustraciones le sirvieran de fuente creativa ${ }^{5}$.

\section{Nuevos crucificados relacionados con la obra de Pablo de Rojas}

Una vez vistas estas anotaciones introductorias que nos sitúan el personaje y algunos pormenores de su obra, se pasará a analizar diferentes piezas que han de considerarse de su

2 LÓPEZ-GUADALUPE MUÑOZ, Juan Jesús, "Pablo de Rojas, encrucijada de las escuelas andaluzas", en La escultura del primer naturalismo, op. cit., pp. 139-174, CRUZ CABRERA, José Policarpo, "Fuentes visuales en la configuración de la escultura quinientista granadina", en Arte y cultura en la Granada, op. cit., pp. 210-212.

3 LÓPEZ-GUADALUPE MUÑOZ, Juan Jesús, "Ut Sculptura Pictura. La integración de las artes plásticas en el primer barroco granadino", en Arte y cultura en la Grana$d a$, op. cit., pp. 412-419.

4 GÓMEZ-MORENO CALERA, José Manuel, "La herencia de Machuca en la pintura del Renacimiento granadino: el retablo de San Francisco del Padul y las tablas de un primitivo sagrario", en Cuadernos de Arte de la Universidad de Granada, 25, Granada, 1994, pp. 25-36.

5 VALVERDE DE AMUSCO, Juan, Historia de la composición del cuerpo humano, Impressa por Antonio Salamanca y Antonio Lafrerij, Roma, 1556; VALVERDE DE AMUSCO, Juan, Anatomia del corpo humano, Impressa por Antonio Salamanca y Antonio Lafrerij, Roma, 1559, factura o de su círculo escultórico, hasta ahora desconocidas.

En las proximidades de la capital granadina, situándose en la zona nororiental, encontramos la localidad de Huétor Santillán, municipio ubicado en el entorno del Parque Natural de idéntico nombre. En el mencionado pueblo hallaremos una de las piezas más destacables y, a la par, prototípicas de su obra en cuanto que sigue miméticamente los estilemas de sus Crucificados más conocidos. La imagen se ubica en la capilla bautismal de la iglesia parroquial de La Encarnación.

Dicho esto, al contemplar la imagen que se ocupa, y analizadas las fuentes, se observa el notable clasicismo y romanismo de la talla, pues evoca al citado dibujo miguelangelesco para Vittoria Colonna (concretamente el de 1540), presentando, asimismo, un enorme parecido con la escultura desnuda que se atribuye también a Miguel Ángel, de la Casa Buonarroti de Florencia, hacia 1492.

La talla, de madera policromada y tamaño académico, representa a Cristo crucificado, clavado con tres clavos, en el momento en que acaba de morir. El efectismo que ese instante produce en el fiel que lo contempla, pretende mudar su ser a la devoción, tal y como enseñaba no sólo Trento, sino también la abundante literatura mística de la época ${ }^{6}$. La imagen no presenta una gran corpulencia, aunque ofrece un estudio anatómico espléndido, siguiendo los parámetros clasicistas. La cabeza, rotunda, se gira exánime hacia su derecha, apoyándose en ese hombro. En este sentido, no resulta tan caída como en el caso del Crucificado del Seminario Mayor de Granada o la del Cristo de los Favores, de la parroquial capitalina de San Cecilio. Su rostro ovalado nos muestra los ojos semiabiertos, al igual que su boca, en esa búsqueda de la humanización de la muerte. Y todo ello arropado, aún más si cabe, por la tonalidad verdosa azulada de los moretones y golpes en la cara. Las cuencas de los ojos no son muy pronunciadas, de igual manera que sus pómulos. $\mathrm{Su}$ nariz recta, al igual que sus cejas, casi conforman entre ellas un ángulo recto. Las mismas, más que talladas, parecen pintadas. Su poblada

\footnotetext{
6 Recuérdense los Ejercicios Espirituales de San Ignacio de Loyola, la literatura de Santa Teresa de Jesús o San Juan de la Cruz acerca de la Pasión de Cristo, amén de las enfervorecidas homilías y pláticas en los púlpitos de dicha temática, que de la época se conservan, así como los grandes sonetos y poesía del Siglo de Oro español. Interesante resulta en este aspecto la siguiente obra: OROZCO DÍAZ, Emilio, Temas del barroco de poesía y pintura, Universidad de Granada, Granada, 1947.
} 
barba, apuntada y bien elaborada en los mechones, se parte en dos en la barbilla. Asimismo, el cabello es trabajado según los cánones que Rojas usa en sus crucificados habitualmente: más o menos en mitad de la cabeza divide el mismo en dos mechones, uno de ellos lo deja caer por el flanco derecho conformando una guedeja pegada al rostro, pero sin llegar a ocultar la oreja como sucede en otros modelos, mientras que el otro lo peina hacia atrás, dejando también al descubierto el pabellón auditivo y continuando la caída sobre la espalda de forma ondulada. Al igual que en otros ejemplos, el maestro alcalaíno no suele tallar la corona de espinas en la pieza. En este caso se denota la ausencia de la misma, que bien pudo ser en su origen metálica como era la costumbre de la época.

En lo referente al resto del cuerpo, los brazos, poco corpulentos, siguen los referentes que Benvenuto Cellini utilizó en el Cristo crucificado del Monasterio de San Lorenzo de El Escorial (1559-1562), y que Pablo de Rojas pudo conocer indirectamente a través de su maestro Rodrigo Moreno, quien presentó para la fundación de Felipe II un Crucificado ${ }^{7}$. La disposición de la figura marca un sutil contrapposto al girar cabeza y pecho hacia la derecha, y sendas piernas al lado opuesto, generando la clásica configuración helicoidal que imprime Pablo de Rojas a sus crucificados. En esta muestra no llega a ser tan marcado como en el Cristo de la Esperanza de la Sacristía de Beneficiados de la $\mathrm{Ca}$ tedral de Granada (1592), por ejemplo. Así pues, el giro del pecho obligará a que se contorsione aún más el hombro izquierdo, separándolo levemente del patibulum. El tórax no es muy voluminoso. No destacan prominentemente los pectorales, pero sí se dibuja la caja o arco torácico, marcándose claramente las costillas, asícomo un abdomen perfectamente definido. Sus piernas esbozan el inicio del sutilcontrappostoque se convertirá en elemento característico de la obra de Rojas, toda vez que las mismas, hasta las rodillas, mantienen la dirección hacia la derecha, mientras que los muslos hacen lo propio hacia el lado contrario. Especial mención hemos de hacer del perizoma o paño de pureza. Suele ser uno de los distintivos o firmas de Rojas. El mismo nos ofrece un dibujo geométrico,

7 BERMÚDEZ DE PEDRAZA, Francisco, Historia eclesiástica de Granada, Universidad de Granada. Editorial Don Quijote, Granada, 1989, fol. 133 ro ${ }^{\circ}$ LÓPEZ-GUADALUPE MUÑOZ, Juan Jesús, "Pablo de Rojas, encrucijada de las escuelas andaluzas”, en La escultura del primer naturalismo, op. cit., pp. 141 y 153. a modo de un doble plegado triangular inclinado hacia arriba. El mayor se vislumbra cubriendo mayormente la zona, mientras que ese segundo pliegue se ve en el muslo derecho. Podemos observar cómo el lienzo se sostiene por un cordón, tallado, a la altura de la cadera, así como el anudado del mismo, que ofrece el característico lazo del que cuelga el habitual pliegue "rojano" bien elaborado y resuelto. Y todo ello policromado en tonalidades doradas, realizando una bella filigrana en el borde del perizoma.

Finalmente, esta imagen, aparte de las fuentes ya citadas, se ha de poner en relación con otras del entorno granadino, como es el caso del Cristo de los Favores, de la iglesia de San Cecilio de la capital granadina, el referido del Seminario Mayor de Granada (anterior a 1580 según el prof. López-Guadalupe $)^{8}$, el de la parroquia de Padul (Granada), el de la parroquial de Quéntar (Granada), el Crucificado de la sacristía de la capitalina Basílica de las Angustias o el Crucificado que se conserva en el Convento de Santa Clara de Lucena (Córdoba). Asimismo, se puede fechar la obra en torno a 1590 aproximadamente, a caballo entre las citadas obras de la granadina Basílica de las Angustias (1582) y la del Cristo de la Esperanza de la Sacristía de Beneficiados de la Catedral de Granada (1592). El estado de conservación de la pieza es óptimo.

Uno de los pocos ejemplos que encontramos de Crucificado expirante que se pueda relacionar con la obra de Pablo de Rojas es el que contemplamos en la zona del Valle de Lecrín, concretamente en la localidad granadina de Melegís, en su iglesia parroquial de San Juan Evangelista. Sin lugar a dudas, la mejor pieza que exponemos en este artículo. La imagen, de madera policromada y tamaño académico, se ubica en la capilla de San Francisco de Paula, y representa a Cristo crucificado con tres clavos en los últimos instantes de su vida. Nuevamente se muestra un hermoso simulacro del naturalismo escultórico granadino, en el que se observa claramente el influjo que tuvo en la imagen el citado dibujo de Miguel Ángel para Vittoria Colonna de 1540.

En líneas generales, la talla presenta los rasgos clásicos de los crucificados de Rojas, como el planteamiento de volúmenes corpóreos no excesivos, con una musculatura matizada, definida y humanizada, en contraposición a modelos

\footnotetext{
8 LÓPEZ-GUADALUPE MUÑOZ, Juan Jesús, “Ut Sculptura Pictura. La integración de las artes plásticas en el primer barroco granadino", en Arte y cultura en la Granada, op. cit., pp. 416.
} 


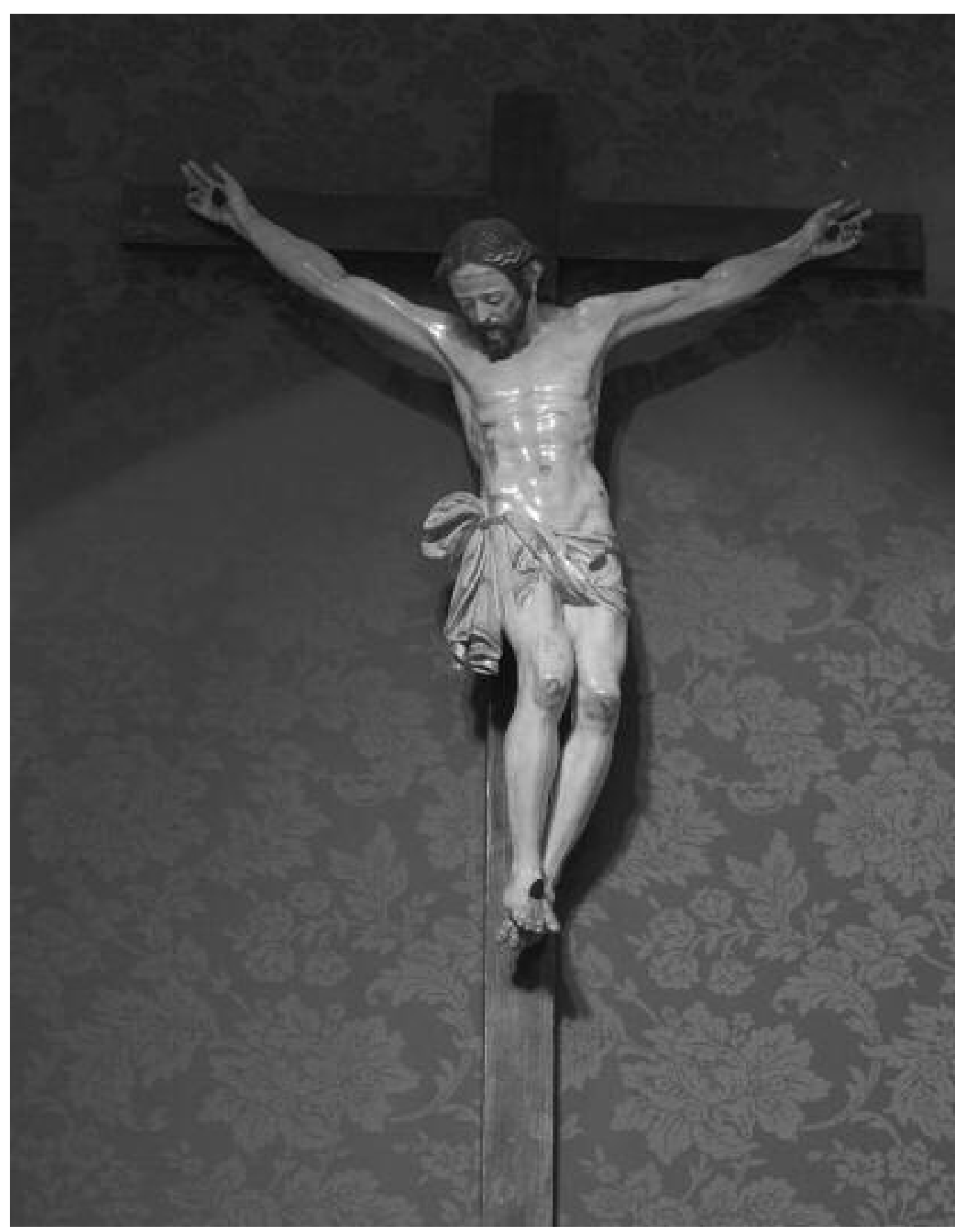

Fig. 1. Crucificado. Atrib. Pablo de Rojas. Iglesia parroquial de La Encarnación. Capilla Bautismal. Huétor Santillán (Granada), finales del siglo XVI o principios del siglo XVII. Foto: José A. Peinado Guzmán [JAPG].

renacentistas que proponen tipos más hercúleos. A pesar de ello, por sus referentes clasicistas, se erige como si de un héroe griego se tratase, con una pose triunfante sobre el patíbulo.

La cabeza, representando el último hálito de Cristo, se gira hacia la derecha a la par que fija su mirada, tremendamente agónica, en el cielo.
En este sentido, la misma hay que relacionarla, evidentemente, con ejemplos de cristos vivos, véase Paciencia de la parroquial capitalina de San Matías, de quien podríamos decir que es "hermana”, o el Nazareno de Priego de Córdoba (Córdoba). El sufrimiento se plasma con nitidez si se observa su boca entreabierta. Se vuelven a rei- 


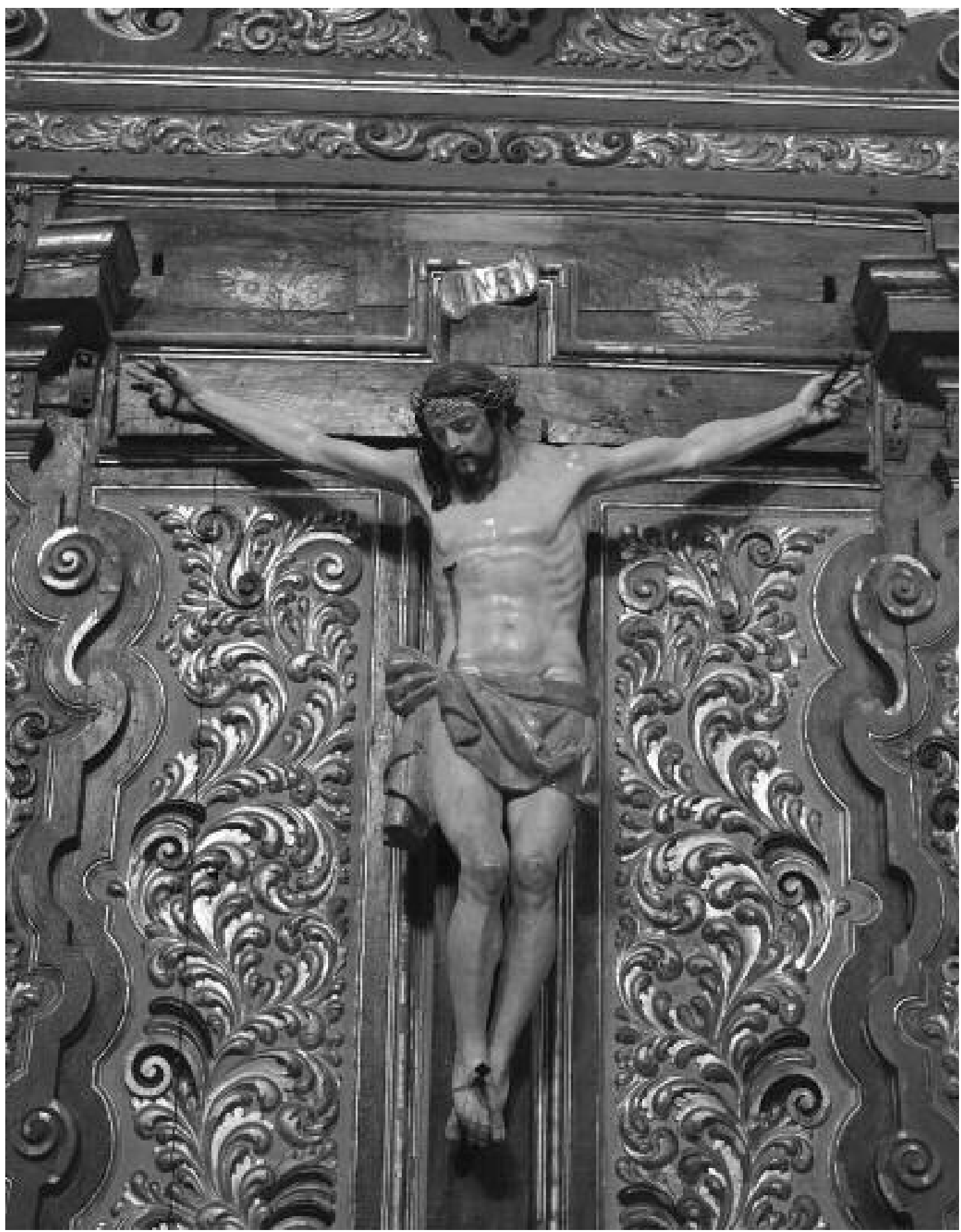

Fig. 2. Crucificado. Círculo de Pablo de Rojas. Iglesia parroquial de La Encarnación. Altar mayor. Huétor Santillán (Granada), finales del siglo XVI o principios del siglo XVII. Foto: JAPG.

terar los estilemas "rojanos" como la nariz recta o los pómulos poco pronunciados, y todo ello aderezado por los característicos moratones de tonalidad verdosa que se aprecian en el rostro. Las cejas se enarcan acompañando la mirada exclamante del Cristo sufriente. Su barba, nuevamente, se nos muestra poblada, bífida y bien tra- bajada en sus mechones. De igual modo, el cabello es notoriamente más voluminoso que en otros ejemplos (v. g. el Crucificado de la sacristía de la Basílica de las Angustias de la capital granadina, aunque también podríamos citar otras muestras relacionadas como el Cristo crucificado de la sacristía de la parroquia de la Asun- 
ción de Priego de Córdoba o el Crucificado del presbiterio de la parroquial de San Pedro y San Pablo de la capital granadina). Aun así, mantiene las características trazas que acostumbra a realizar en la elaboración del pelo. Tampoco en esta muestra se aprecia el tallado de la corona de espinas, tal y como suele ocurrir en los crucificados del maestro alcalaíno.

En lo concerniente al cuerpo, independientemente de los referentes ya citados, contemplamos un estudio anatómico magnífico, acorde con el naturalismo escultórico del que bebe Pablo de Rojas. Los brazos no se observan musculosos. La disposición de la figura marca un leve contrapposto, dibujándose una línea zigzagueante al inclinarse las piernas hacia la derecha, muslo y torso hacia la izquierda, y nuevamente la cabeza virando a la diestra. Sutilmente, pues, desarrolla la forma helicoidal que Pablo de Rojas ejecuta en muchos de sus crucificados, especialmente acuciado en el referido Cristo de la Esperanza de la Sacristía de Beneficiados de la catedral granadina.

Interesante resulta el giro del pecho hacia la derecha, lo que obliga a que se contorsione el hombro diestro, justamente la resolución opuesta a la que acostumbra a marcar en sus crucificados ya muertos, toda vez que la cabeza de éstos tiende a girarse al lado contrario, siendo el hombro izquierdo el que se fuerza. Ese movimiento repercute nuevamente en una mínima separación del cuerpo con respecto al madero de la cruz. Al igual que en otros referentes, no se aprecia un tórax musculoso. Aun así, la espléndida anatomía de la figura permite vislumbrar una correcta definición tanto del arco torácico como de las costillas y abdomen. Con respecto al perizoma, es reseñable que, aunque mantiene las formas de Pablo de Rojas en líneas generales, difiere mínimamente de la mayoría de los ejemplos, al desaparecer el pequeño pliegue triangular sobre el muslo derecho de la imagen. Es, si cabe, aún más minimalista en cuanto al concepto. Un paño de pureza similar lo contemplamos en el Crucificado del Convento de Santa Clara de Lucena (Córdoba).

Finalmente, esta pieza, reseñadas las muestras ya mencionadas, es difícil ponerla en conexión con otras imágenes de forma estrictamente mimética, ya que apenas hallamos referentes de cristos expirantes en la obra del maestro de Alcalá La Real. Por tanto, resulta muy interesante sacar a la luz esta talla por su originalidad y excepcionalidad. La obra, recientemente restaurada, presenta un inmejorable estado de conservación.

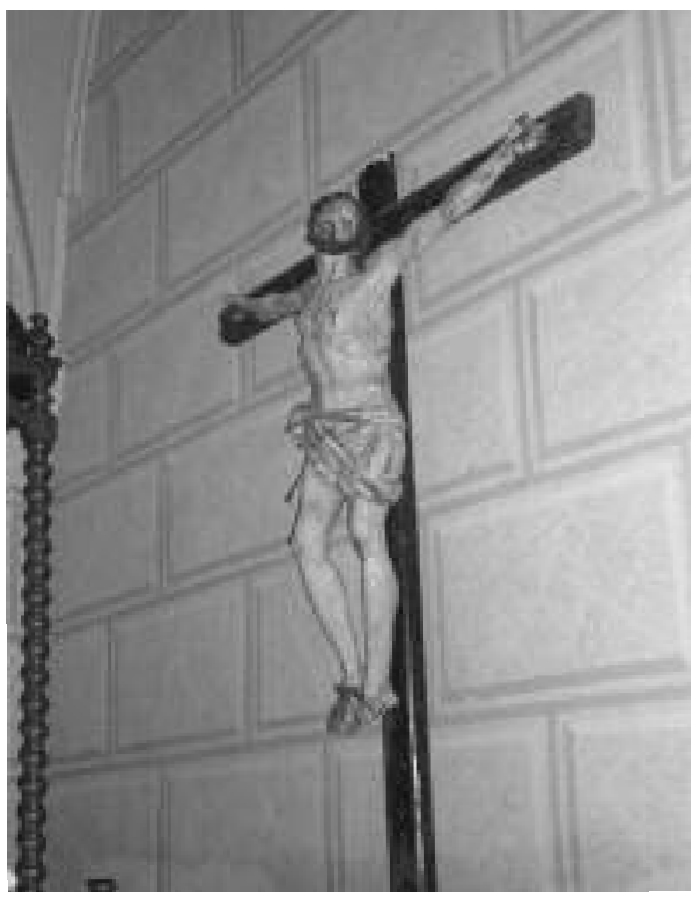

Fig. 3. Crucificado expirante. Atrib. Pablo de Rojas. Iglesia parroquial de San Juan Evangelista.Capilla de San Francisco de Paula. Melegís (Granada), finales del siglo XVI o principios del siglo XVII. Foto: JAPG.

Crucificados relacionados con el círculo de $\mathrm{Pa}$ blo de Rojas

Entrando ya a valorar la obra del círculo o del taller de Rojas, en la ya citada parroquial de Huétor Santillán, se encuentra otra muestra relacionable con las gubias y el estilo del escultor alcalaíno. La misma, de madera policromada, se halla en un pequeño retablo en el muro del evangelio del citado templo. El simulacro representa la figura de Cristo que acaba de morir, con ojos y boca entreabiertos. La pieza, de tamaño natural, no acusa en exceso las formas helicoidales acostumbradas en los rasgos de Rojas. El pecho se aprecia notoriamente más musculoso de lo que suele ser habitual en las trazas del escultor giennense, con una resolución magnífica. Evoca, en este aspecto, al Crucificado del Seminario Mayor de Granada o a las formas de Nuestro Padre Jesús de la Paciencia, de la parroquial capitalina de San Matías. Incluso lo podíamos vincular a algunas imágenes del discípulo Alonso de Mena, como el Crucificado de la iglesia de Santa María de la Alhambra (Granada), en lo referente a su volumen. Aun así, a diferencia del ejemplo previamente descrito, la factura de esta imagen se observa más tosca y con un menor grado de definición, en líneas generales, por lo que probablemente se esté tratando de un ejemplo de su taller o círculo. 


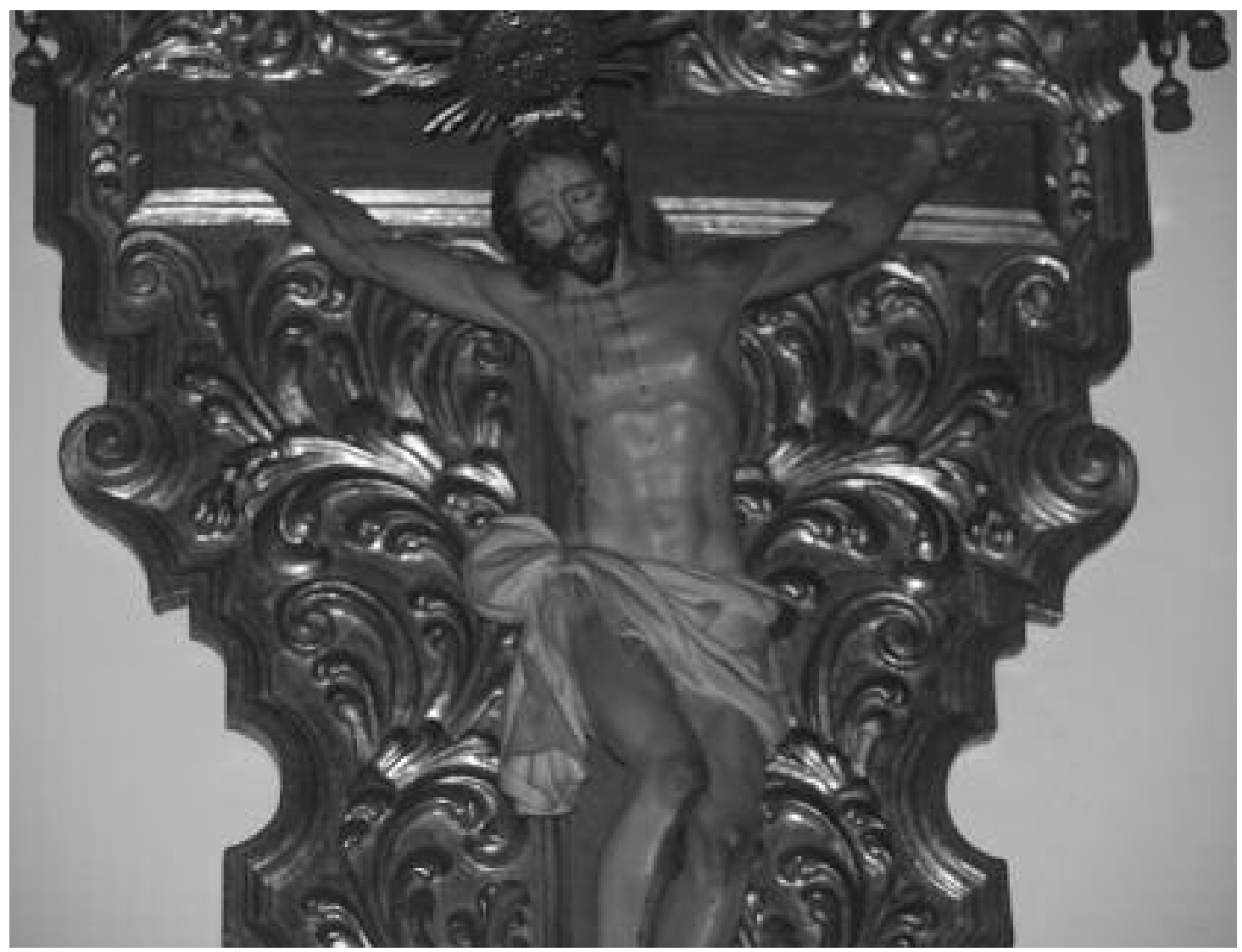

Fig. 4. Crucificado. Círculo de Pablo de Rojas. Convento de la Piedad. Sacristía. Granada, finales del siglo XVI o principios del siglo XVII. Foto: JAPG.

Aunque las piernas giran muy levemente hacia la derecha, predomina visualmente una pose más centrada de las extremidades, detalle muy característico en tallas del referido Mena, por ejemplo. La longitud de las piernas es menor que la de otras imágenes vinculadas a $\mathrm{Pa}-$ blo de Rojas. Con respecto al perizoma, si bien son reconocibles los estilemas del alcalaíno, la ejecución del mismo denota una factura poco conseguida. Este tipo de formas, escasamente definidas, suelen ser prototípicas de imágenes de retablo que se contemplan a cierta distancia, aunque este caso en particular no respondería a dicha casuística.

La cabeza sigue los cánones naturalistas que esboza el maestro alcalaíno. La disposición del cabello, en líneas generales, suele ser la acostumbrada en su obra, aunque llama la atención el mechón suelto que cae por el flanco derecho, correctamente elaborado, y que difiere de las resoluciones habituales que tiende a usar en los crucificados. En cierto modo, recuerda a las líneas utilizadas en obras como el citado Jesús de la Paciencia o el San Juan Evangelista de la catedral granadina, así como en algunas Inmaculadas. Su barba bífida muestra unos mechones bien tra- bajados, percibiéndose el característico bigote arqueado que suele realizar en sus obras.

El rostro nos ofrece también un claro modelo "rojano", de rasgos ovalados, con nariz y cejas rectas, ojos inclinados y rasgados, así como cuencas y pómulos no muy pronunciados. El pabellón auditivo izquierdo, asimismo, no se oculta con el pelo como acostumbra a ejecutar.

La imagen, que aparte de los ejemplos ya mencionados se puede relacionar con las primeras tallas que realizara Alonso de Mena en la Alpujarra granadina (v. g. el Crucificado de Trevélez), sería datable en los primeros años del siglo XVII. La pieza se halla en buen estado de conservación.

Dentro de las obras que consideramos afines al círculo de Pablo de Rojas, se ha de destacar el Crucificado que se encuentra en la sacristía del Convento de la Piedad de Granada. La imagen es de madera policromada y pequeño tamaño, estando colocada en una cruz insertada dentro de un pequeño retablo dosel, de tonalidad dorada con decoración de tipo vegetal. Representa el simulacro de Cristo muerto y crucificado con tres clavos.

A nivel genérico son apreciables los estilemas de Pablo de Rojas en la obra. Nuevamente 


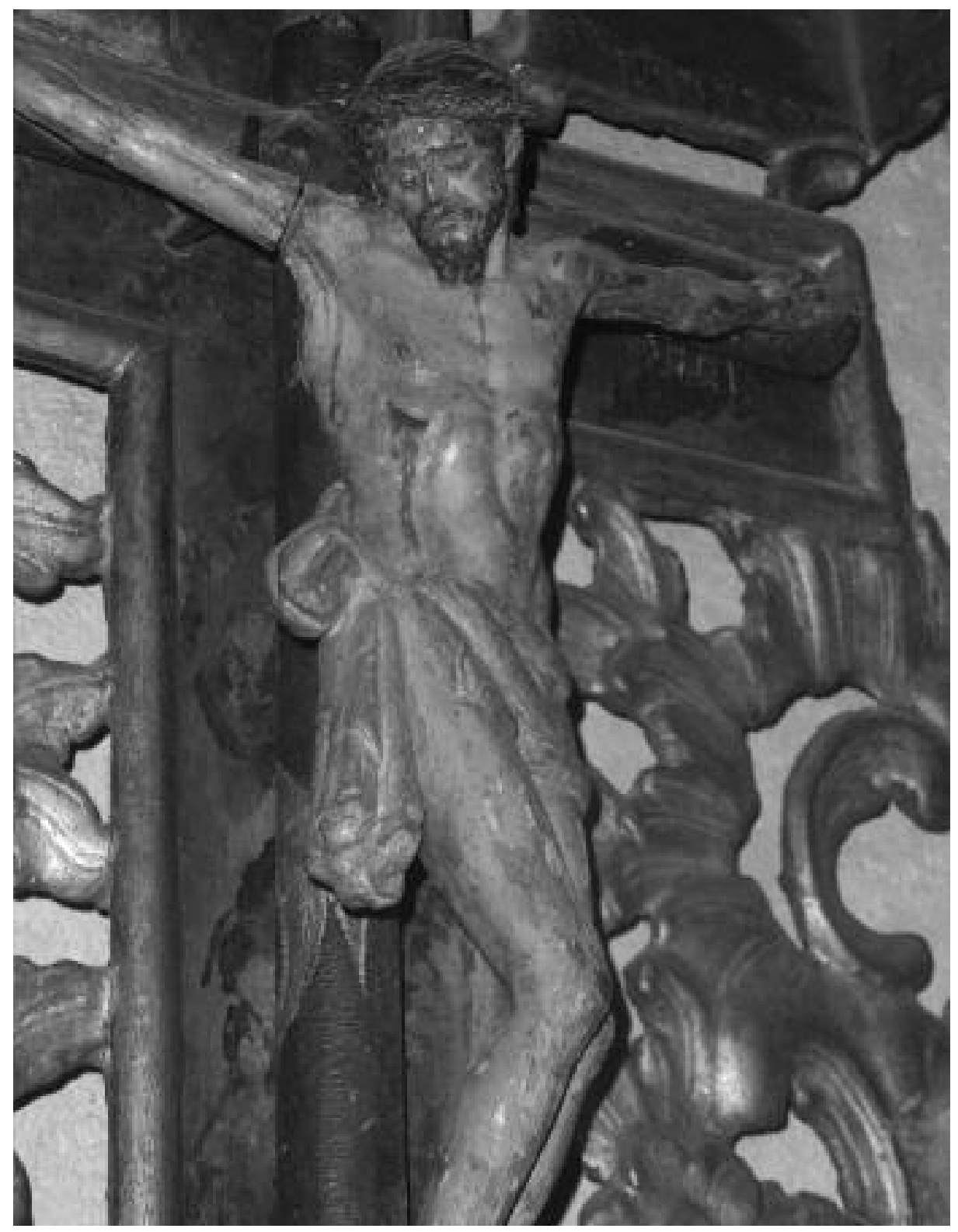

Fig. 5. Crucificado. Atrib. Diego de Vega. Iglesia parroquial de La Encarnación. Dependencias parroquiales. Montefrío (Granada), finales del siglo XVI o principios del siglo XVII. Foto: JAPG.

se contemplan los cánones del naturalismo escultórico, reseñándose el estudio anatómico de la talla. Es destacable observar, a primera vista, cómo el cuerpo se descuelga levemente y no se mantienen los brazos tan paralelos al patibulum como en otras muestras.

En la cabeza se reiteran las formas "rojanas" identificables en el rostro ovalado, ojos y boca entreabiertos, con labios notoriamente amoratados en este ejemplo, nariz y cejas rectas, así como pómulos no muy acuciados. La policromía verdosa en determinadas zonas faciales acentúa el dramatismo de la imagen. La barba bífida mantiene las trazas de Pablo de Rojas, aunque el bi- gote difiere de las mismas, siendo de líneas más rectas, a diferencia de los clásicos modelos de $\mathrm{Pa}$ blo de Rojas, que tienden a efectuar una línea ondulada a modo de arco. Asimismo, el cabello se contempla voluminoso y bien trabajado en sus mechones, siguiendo el estilo del Nazareno de Priego de Córdoba, Nuestro Padre Jesús de Paciencia y Penas, imágenes ya citadas, así como el Crucificado de Quéntar (Granada). Tampoco se contempla en este ejemplo el tallado de la corona de espinas. Lo que sí se ve es un nimbo circular con ráfaga metálica que exorna la testa.

En lo referente al cuerpo, independientemente de lo ya reseñado de sus formas clásicas y de 
su excelente anatomía, destaca el detalle ya comentado de mostrarse un tanto descolgados los brazos de la cruz. Igualmente, se constata el habitual contrapposto con líneas esbozadas hacia la derecha y, posteriormente, a la izquierda tal y como se ha analizado en otras muestras. La definición de volúmenes repite el proceder que el maestro alcalaíno imprime a sus crucificados. También el paño de pureza sigue el tratamiento acostumbrado en la obra de Rojas. En este sentido, resultaría reiterativo detenerse a describir esquemas similares que se reproducen en su canon de crucificados.

Para concluir, al relacionar esta imagen con otras tallas, si bien no encontramos un referente mimético de la misma, podemos vincularla con cualquiera de los ejemplos que a lo largo de este trabajo hemos referido, en mayor o menor grado. La obra se encuentra en buen estado de conservación.

La última pieza que se trae a colación también formaría parte del elenco de tallas que se insertarían en el círculo de Pablo de Rojas y sus seguidores. Concretamente podría asociarse con la obra de Diego de Vega, escultor formado con Pablo de Rojas y que desarrollará gran parte de su trabajo en la zona de Málaga. La imagen se encuentra en las dependencias parroquiales de la iglesia de La Encarnación de la granadina localidad de Montefrío. Notoriamente se aprecia una menor calidad con respecto a las tallas que se han descrito previamente. La imagen, de madera policromada y pequeño tamaño como la anterior, también se inserta dentro de un minúsculo retablo. Probablemente se trate de la talla que exornaba en su origen el púlpito. Representa a Cristo ya muerto y crucificado con tres clavos.

En líneas generales se observan las trazas del maestro alcalaíno y el clasicismo de sus formas. La mayor estilización de la figura con respecto a cómo la concibe Pablo de Rojas, permite vincular esta talla a la obra del citado Vega.

En la cabeza son reconocibles las trazas habituales que caracterizan la creación del genio jiennense, a pesar del estado de deterioro que presenta la imagen. La barba, apuntada, no se aprecia bífida, de igual modo que el bigote difiere de los modelos "rojanos". Este detalle es reconocible en los cristos de Diego de Vega, al igual que las cejas casi pictóricas. El cabello, sin embargo, mimetiza el esquema de Pablo de Rojas. Exorna su testa una pequeña corona de espinas metálica.

En lo relativo al cuerpo, el mismo se vislumbra notoriamente alargado y con una correcta ejecución anatómica. El mismo se percibe definido, siguiendo los cánones que habitúa el modelo del maestro de Alcalá La Real al respecto.
Del mismo modo, vemos el clásico contrapposto que marca la figura y que ya hemos descrito en anteriores ejemplos. Finalmente, el perizoma, de hechuras más toscas, reitera el formato más conocido de los paños de pureza "rojanos".

Se puede asociar esta imagen con el Cristo de la Buena Muerte de Antequera (1582) del referido Diego de Vega. La talla presenta un mejorable estado de conservación, requiriéndose que se acometa una preceptiva restauración de la misma.

\section{Conclusiones}

El magisterio de Pablo de Rojas se extendió notoriamente por la geografía granadina y su entorno, manifestándose también en zonas de Almería, Jaén, Málaga y Córdoba. Sus numerosos discípulos como el gran Juan Martínez Montañés, Bernabé de Gaviria, Alonso de Mena, Diego de Vega o los hermanos Juan y Antonio Gómez dan muestra de ello. En este sentido, las formas manieristas del genio de Alcalá La Real insertaron a la escuela granadina de escultura en el Barroco.

Centrándonos en el modelo iconográfico del Crucificado, a lo largo de este trabajo de campo se han ido aportando algunas piezas que, desde un análisis meramente estilístico, pueden considerarse de sus gubias o de su círculo de escultores. Lamentablemente, a la hora de establecer una certera autoría de las piezas nos encontramos con un doble problema. Por un lado, los acontecimientos bélicos de la Guerra Civil en el verano de 1936, esquilmaron los archivos parroquiales y sus valiosos documentos. Por otro lado, otra fuente importante de información, como es el Archivo de Protocolos Notariales de Granada, sufrió un desolador incendio en la Navidad de 1879, perdiéndose la inmensa mayoría de los contratos artísticos de la ciudad y alrededores. Por tanto, exceptuando contados casos, resulta enormemente difícil la documentación exhaustiva de estas obras artísticas. Según esto, este artículo se ha basado, sobre todo, en un extenso trabajo de campo por el arzobispado de Granada, especialmente por las zonas más alejadas del mismo (v. g. Las Alpujarras, Valle o Poniente), analizando por comparativa estilística las distintas tallas con otras piezas más conocidas y que la investigación da por consabidas de uno u otro autor. Por tanto, y para ello, se muestran fotografías propias del autor y desconocidas de estas tallas, que servirán para un mejor conocimiento de este período artístico y de sus escultores. 